\title{
Cathodic delamination of polymer coatings from metals. Mechanism and prevention methods. A review ${ }^{1}$
}

\section{M.A. Petrunin, (i) L.B. Maksaeva, (i)* N.A. Gladkikh, (i) T.A. Yurasova, M.A. Maleeva ${ }^{\circledR}$ and V.E. Ignatenko}

A.N. Frumkin Institute of Physical Chemistry and Electrochemistry, Russian Academy of Sciences, Leninsky pr. 31, 119071 Moscow, Russian Federation

*E-mail: Imaksaeva@mail.ru

\begin{abstract}
The phenomenon of cathodic delamination of protective polymer coatings from a metal and the development of methods for its prevention are important scientific and technical problems in the operation of underground and underwater metal structures protected from corrosion by insulating polymer coatings. A review of scientific and technical literature on the cathodic delamination of anticorrosive polymer coatings from metals is presented. The possible mechanisms of cathodic delamination are considered, including the cathodic reduction of a metal oxide, electrochemical destruction of a polymer layer adjacent to the surface, destruction of interphase bonds under chemical attack by cathodic reaction products, and mechanical action of gaseous molecular hydrogen formed at the metal-polymer interface due to the cathodic reduction of water. The following factors that determine the rate of this process are identified and discussed: the potential of cathodic protection, thickness of the polymer coating, temperature, ionic composition of the electrolyte, and time of testing or operation of a structure under working cathodic protection. The methods for inhibiting cathodic delamination presented in the literature are briefly described. The mechanism of inhibitive action of surface layers that are formed on a metal upon pretreatment and efficiently slow down the delamination of a polymer coating under cathodic potential is considered. Various methods for the modification of coatings are discussed, namely: incorporation of pigments, adhesion promoters, corrosion inhibitors, conductive polymers, or functionalized particles of graphene oxide or carbon nanotubes into the coating bulk, etc., are considered. The effect of various methods of coating modification on the adhesion in the dry state, water resistance of coating adhesion, liability of the coating to cathodic delamination, and anticorrosion characteristics of the coating are considered.
\end{abstract}

Key words: adhesion, metal corrosion, polymer coatings, cathodic delamination, pipe steel, polymer coatings, organosilanes, surface pretreatment.

Received: October 16, 2020. Published: December 29, 2020

doi: $\underline{10.17675 / 2305-6894-2021-10-1-1}$

\footnotetext{
${ }^{1}$ This work was financially supported by the Program for Basic Research of the Presidium of the Russian Academy of Sciences No. 4P "Current problems of surface physicochemistry and creation of new composite materials".
} 


\section{Introduction}

The majority of steel structures in operation are protected from corrosion by paint and polymer coatings [1]. However, the electrochemical processes occurring on a metal can strongly affect the protective properties of coatings [2]. In the initial period of operation, the metal corrosion rate is low and is controlled by the adhesion at the metal-polymer interface $[2,3]$ where the coating is saturated with the aqueous electrolyte and oxygen. It is believed that the barrier properties of a coating with respect to oxygen and water affect corrosion insignificantly [3, 4]. This follows from the fact that the rate of underfilm corrosion of a metal is much smaller than the diffusion rates of the components required for the corrosion process. However, the presence of defects in a coating or local loss of adhesion can significantly accelerate the electrochemical processes and underfilm corrosion of the metal [2]. In case of steel corrosion in a defect in an aqueous electrolyte, the coating around the defect cathodically delaminated from the metal. The delamination rate can reach $0.7 \mathrm{~cm}^{2} / \mathrm{h}$ $[2,5]$ and is determined both by the diffusion of oxygen and water through the coating and the diffusion of electrolyte cations through the coating-metal interface [5], and can increase significantly if steel is cathodically polarized.

On the other hand, electrochemical protection (ECP) is one of the most efficient and popular methods of combating corrosion of underground and underwater metal structures and facilities [6,7]. Defectiveness of insulation is observed quite often under real operating conditions, and on applying cathodic polarization to a metal protected by a polymer coating with through defects, the polymer coating quickly loses adhesion and protective properties. This phenomenon is called "cathodic delamination of coatings". It was originally described by Evans in 1929 [8]. The loss of adhesive contact is usually associated with the simultaneous action of the alkali formed in the cathodic oxygen reduction reaction and mechanical stress. Cathodic delamination is of great practical importance. This explains the attention paid to it by researchers from different countries who determined the reasons of this phenomenon and developed methods to combat it. Cathodic delamination was studied most intensely in the second half of the 20th century and in the early 21 st century $[3,5,9-$ 22]. It was found that cathodic delamination was a very complex process. Researchers found it difficult to single out the main reason for the delamination of coatings under cathodic polarization $[5,14,15,19]$. The possible mechanisms of delamination of cathodic coatings will be discussed below.

The many years of attention of researchers and practitioners focused on this problem $[3,5,9-22]$ resulted in the development of principles for the standardization of tests for the resistance of coatings to cathodic delamination in international regulatory documents [2328]. This simplifies the selection of insulating coatings for underground and underwater structures. However, the current lack of a clear understanding of the cathodic delamination mechanism complicates the scientifically-based development of efficient ways to combat this phenomenon and, as a result, the market appearance of anti-corrosion coatings that are 
not subject to cathodic delamination and retain high protective characteristics under operating cathodic protection of a metal structure.

In this work, we made an attempt to generalize the experience accumulated by researchers in the study of cathodic delamination of polymer coatings and in the development of methods to combat this phenomenon.

\section{Delamination mechanism}

Numerous works are available in the literature that cover a wide range of systems, and at first glance it seems that there is no consensus among researchers. It has been found that cathodic delamination is a very complex process and researchers find it difficult to pinpoint the main reason for the delamination of coatings. However, closer examination makes it obvious that there are three main mechanisms suggested for explaining the reasons of cathodic delamination [16]. They have one feature in common: when the cathodic reaction 1 occurs, an alkali is generated on the metal surface [2, 5, 29-32], which results in an extremely high $\mathrm{pH}$ under the coating near the delamination area. The $\mathrm{pH}$ value under a coating can exceed $14[5,31]$.

$$
\mathrm{H}_{2} \mathrm{O}+\frac{1}{2} \mathrm{O}_{2}+2 e^{-}=2 \mathrm{OH}^{-}
$$

The mechanisms of cathodic delamination of coatings described in the literature can be classified as follows: a) electrochemical reduction of the metal oxide [16]; b) alkaline hydrolysis [17] or electrochemical destruction [33] of the near-surface polymer layer that is responsible for the formation of adhesive bonds with the surface; c) alkaline destruction of interphase bonds [16].

In addition to the above, other cathodic delamination mechanisms are also possible. For example, it is believed [34] that the polymer layer responsible for the adhesive interaction with the metal at the interface undergoes destruction due to attack by free radicals formed in the reaction between $\mathrm{Fe}^{2+}$ and $\mathrm{H}_{2} \mathrm{O}_{2}$ (2) or by organic peroxides [35]. Peroxide compounds are intermediates in the cathodic oxygen reduction reaction 1 . They react 2 with ferrous cations present in the electrolyte near the metal-polymer interface. The degradation of the polymer layer near the metal surface under the action of free radicals results in the degradation of adhesive bonds and, hence, accelerated delamination of the coating [29, 34, 35]. Moreover, cathodic polarization of a metal results in reaction 3 with evolution of gaseous hydrogen on its surface [31]. The evolution of molecular gaseous hydrogen at the metal-polymer interface can cause a high pressure and additional mechanical stress at the delamination tip (Figure 1) that is directed normally to the metal surface and favors the coating delamination [30-32]. This is confirmed by the identified correlation between the current of electrolytic hydrogen incorporation into the metal and the rate of cathodic delamination [31].

$$
\begin{gathered}
\mathrm{Fe}^{2+}+\mathrm{H}_{2} \mathrm{O}_{2} \rightarrow \mathrm{Fe}^{3+}+\mathrm{OH}^{\cdot}+\mathrm{OH}^{-} \\
2 \mathrm{H}_{2} \mathrm{O}+2 e^{-}=\mathrm{H}_{2}+2 \mathrm{OH}^{-}(a q)
\end{gathered}
$$


The cathodic delamination of polymer coatings from metal surfaces was studied in detail in a series of works $[4,5,14,16]$. As a result, the processes occurring on a metal surface in the presence of a polymer coating under cathodic polarization were detailed. Figure 1 shows these processes schematically and illustrates all the mechanisms of cathodic delamination suggested in the literature described above.

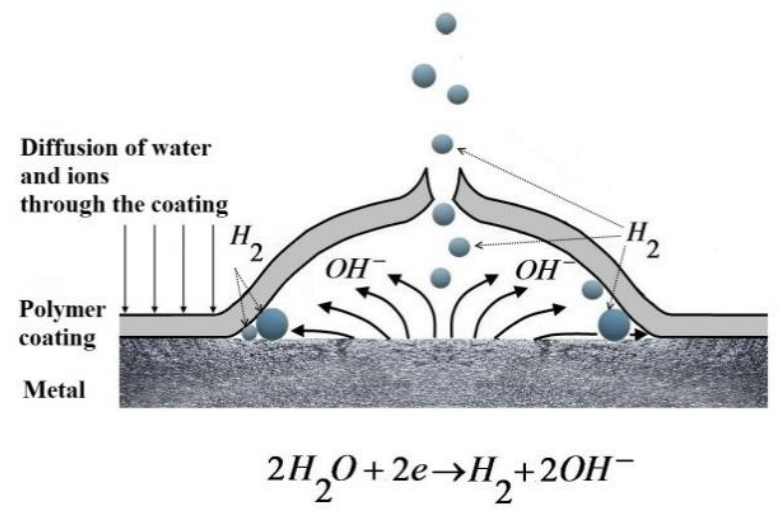

A

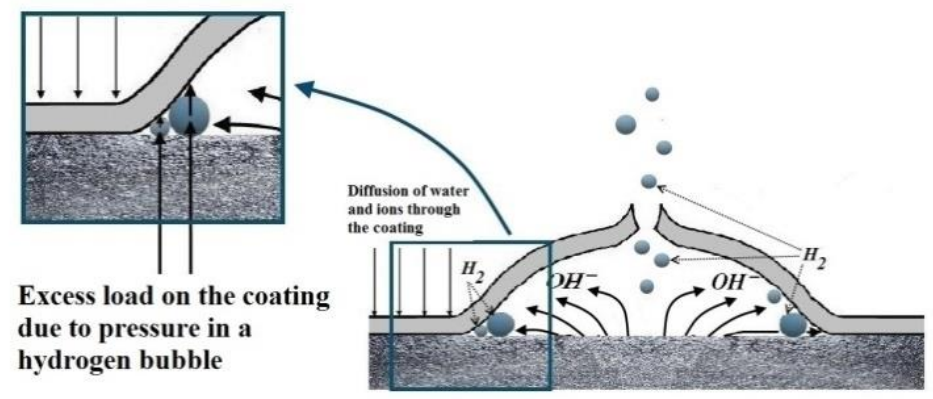

B

Figure 1. Scheme of the processes that occur in a defective polymer coating and result in the cathodic delamination of the coating. $\mathbf{A}$ - processes in a defect and under a delaminated coating; $\mathbf{B}$ - processes in a defect and under a delaminated coating with details of the metalpolymer interface and the coating delamination zone.

The degradation of the metal-polymer adhesive contact due to the combined action of $0.5 \mathrm{M} \mathrm{NaCl}$ solution and a cathodic potential of $-1.5 \mathrm{~V}$ is shown schematically in Figure 1. The appearance of the defective coating after 1000 hours of testing was as follows: a blistered central region and a weakly adhering external zone more distant from the defect. Reduction of the metal oxide at the edge of the blistered region was identified by X-ray photoelectron spectroscopy (XPS) [16]. The appearance of metallic components in the spectrum indicated that the oxide thickness was significantly reduced in comparison with the center of the delaminated region [16]. It is believed $[4,5,16]$ that a $\mathrm{pH}$ increase at the tip of the delaminated coating (Figure 1b) results in dissolution of the oxide, but as the crevice (the distance from the metal to the delaminated coating) grows, the $\mathrm{pH}$ decreases and the oxide thickness increases again. XPS studies [16] inside a delaminated area (blister) showed the presence of a very clean (oxide-free) metal surface under the coating, which, according to the authors, might indicate that the oxide surface layer undergoes reduction or dissolution and hence intraphase degradation of interfacial bonds occurs that causes delamination along the metal/metal oxide interface with removal of the oxide from the surface together with the delaminated coating [16]. Outside the delamination area, the coating is easily delaminated, without breaking, from the surface of the metal substrate. It is noted that the degradation is related to the interfacial region where a fraction of the polymer remains on the substrate surface, as follows from the large amount of carbon and a lowintensity signal of iron in the XPS spectrum [16]. In this case, the authors refer to the 
hydrolysis of the coating layer adjacent to the coating interface. The hydrolysis is due to the action of water molecules that penetrated into the polymer bulk by diffusion through the polymer film. In addition, the effect of the solution composition and, in particular, the effect of the cation nature on the cathodic delamination was studied. Experiments with $1^{\text {st }}$ and $2^{\text {nd }}$ group metal chlorides showed that the rate of cathodic delamination depended on the size of the hydrated cation [14].

\section{Factors affecting the cathodic delamination of polymer coatings}

It is believed [37] that there are two types of parameters that strongly affect the resistance of organic coatings to cathodic delamination. The first type includes the physicochemical parameters, such as the applied cathodic potential, coating thickness, electrolyte, test temperature, time, etc. The parameters of the second type correspond to the coating composition only. External factors, such as temperature, applied cathodic potential, and chemical composition of the electrolyte, which affect the rate of cathodic delamination of a highly structured epoxy coating, were studied in detail [37]. It that study [37], electrochemical impedance spectroscopy was used to estimate the anticorrosive properties of the coating and to study the effect of applied cathodic potential on the barrier properties of the coatings studied by continuous monitoring the delamination zone size and the processes of bubble formation, cracking and discoloration (chalking) of the coating.

A study on the effect of coating thickness, the other test parameters being unvaried $(E=-1.5 \mathrm{~V}$ relative to the saturated silver chloride electrode $(\mathrm{Ag} / \mathrm{AgCl})$; room temperature; a ternary salt in accordance with the standard test conditions [26] as the electrolyte) showed that the radius (propagation zone) of cathodic delamination decreased with an increase in the coating thickness [37]. An almost inverse linear dependence of cathodic delamination for an epoxy coating was found in the thickness range of 100-400 $\mu \mathrm{m}$ [37]. Moreover, no such linear relationship was observed for alkyd coatings in tests on a primer coating layer [4]. It is believed $[4,37]$ that the linear dependence up to a certain threshold thickness is due to an increase in the barrier properties of the coating. Cathodic delamination tests failed to differentiate the resistance to cathodic delamination at coating thicknesses exceeding a threshold value [37]. At coating thicknesses below $400 \mu \mathrm{m}$, multiple bubbles and slight chalking were observed during the tests. On reaching a thickness of $400 \mu \mathrm{m}$, the coating became totally resistant to cathodic delamination, and above this thickness, no delamination occurred within 30 days of testing.

It was found [38] that the delamination zone decreased exponentially with an increase in the coating thickness in the range from 400 to $1250 \mu \mathrm{m}$. A number of standardized test methods were used [38], however, the exact method which showed an exponential plot of cathodic delamination rate on the coating thickness was not specified.

It is noted in the literature [37-39] that the applied cathodic potential that strongly affects the delamination rate is among the most significant factors determining the cathodic delamination of organic coatings. Many researchers studied the effect of applied cathodic potential in the range from the potential of iron free corrosion $(-750 \mathrm{mV} v s$. SCE) to 
$-1000 \mathrm{mV}[10-22,34]$. In those experiments, the potential of the metal in the coating delamination area increases to the corrosion potential or above, which favors the corrosion of the metal substrate. It was noted [37] that the methods used to estimate the protective properties of coatings in industry often involve the polarization of a coated metal at potentials more negative than $-1000 \mathrm{mV}$, which helps suppress the corrosion in the defect zone but causes other types of coating damage, such as faster delamination, chalking, binder hydrolysis, etc. In [37], the cathodic potential was varied in the range from -1000 to $-2500 \mathrm{mV}$ (with respect to the silver chloride electrode) while the other external parameters were not varied. The effect of applied cathodic potential on the delamination of an epoxy coating was studied at two coating thicknesses: 200 and $400 \mu \mathrm{m}$. The expected result that application of a more negative potential increased the delamination rate was obtained. At a lower coating thickness $(200 \mu \mathrm{m})$, delamination rapidly increases due to a change in the applied cathodic potential from -1000 to $-2500 \mathrm{mV}$. In delamination tests, shifting the applied potential towards more negative values increased the cathodic reaction rate, which resulted in the evolution of a greater amount of gaseous hydrogen. The higher rate of cathodic reaction is counterbalanced by an increase in the rate of the anodic reaction at the counter electrode. This, in turn, increases the alkalinity in the immediate vicinity and in the electrolyte bulk, thereby increasing delamination. In contrast to the thinner coating $(200 \mu \mathrm{m})$, the coating with a thickness of $400 \mu \mathrm{m}$ showed a gradual slow increase in the delamination zone on shifting the applied cathodic potential from -1000 to $-1500 \mathrm{mV}$, but after the potential was shifted to $-2500 \mathrm{mV}$, the delamination rate increased rapidly. The effect of applied cathodic potential on the cathodic delamination did not change on varying the coating thickness. It is noted [37] that higher delamination rates at more negative potentials even at a coating thickness of $400 \mu \mathrm{m}$ indicate that delamination occurs not due to poor barrier properties of the coating but due to a higher alkalinity at the metal-coating interface near a defect.

In addition to studies on the effect of the coating potential and thickness, the same authors [37] studied the relationship between cathodic delamination and the nature of the electrolyte. They compared the effect of various electrolytes recommended in standard test methods on the cathodic delamination rate. As a result, it was found that in the case of one salt $(3 \% \mathrm{NaCl})$, a higher rate of cathodic delamination was observed than in a mixture of three salts (1\% each of $\mathrm{NaCl}, \mathrm{Na}_{2} \mathrm{CO}_{3}$, and $\mathrm{Na}_{2} \mathrm{SO}_{4}$ ) in a wide range of temperatures and applied cathodic potentials [37]. The authors explain this by a number of factors, such as a lower buffering capability of $\mathrm{NaCl}$, a lower $\mathrm{pH}$ of $\mathrm{NaCl}$ solutions leading to an acceleration of the cathodic reaction, a higher concentration of hypochlorite formed in the anodic reaction, or a combination of these factors.

A detailed study on the effect of temperature has shown [37] that it is a critical factor affecting the rate of cathodic delamination. It is well known [40] that some properties of a polymer, such as water permeability, elasticity, etc., change at temperatures above its glass transition temperature $\left(T_{\mathrm{g}}\right)$. It was found that the $T_{\mathrm{g}}$ of the base polymer coating studied in [37] was $\sim 55^{\circ} \mathrm{C}$. Hence, the highly elastic epoxy coating studied softens above this 
temperature and its permeability increases. The increase in water permeability results in the formation of additional cathodic reaction sites at the metal-coating interface in addition to those located near a defect. The formation of hydrogen or reduction of oxygen on these areas results [37] in two situations: (1) upon formation of any gas at a metal-coating interface, a pressure develops that pulls the coating upward, thus causing the formation of bubbles, and (2) the formation of any particles (usually ions) creates a concentration gradient between the interface and the electrolyte bulk. This gradient favors a growth in the osmotic pressure and formation of bubbles, inside which gaseous hydrogen can be formed. In turn, it creates an additional pressure at the interface that favors delamination (Figure 1b). The authors performed thermal tests of the coating and showed that at temperatures above $T_{\mathrm{g}}$, the rate of electrolyte diffusion through the coating increases, thereby causing a higher rate of cathodic delamination. Thus, it was noted [37] that an increase in the temperature of the coating base polymer above $T_{\mathrm{g}}$ strongly affects the resistance to cathodic delamination. Other parameters, such as the electrolyte composition and applied cathodic potential, increase the rate of cathodic delamination in tests at higher temperatures [37].

In addition to the effect on cathodic delamination, the effect of the cathodic potential on the barrier properties of the epoxy coating was studied [37]. It was noted that it is rather difficult to predict how the barrier properties of an organic coating would change under an applied cathodic potential. If the coating acts as an ideal barrier or insulator for an electrolyte, no cathodic reaction occurs at the metal-coating interface. However, over time, on exposure to a corrosive environment, water penetrates and accumulates at the coating interface and provokes a cathodic reaction. Estimation of changes in the coating resistance with time and on immersion in a chloride-containing electrolyte with or without cathodic polarization showed that the coating exhibited very high resistance at an early stage of immersion in $3.5 \%$ sodium chloride solution. The transient electrical resistance of the coating in the absence of cathodic polarization after 20 days of exposure in a chloride-containing solution was $108 \mathrm{Ohm} \cdot \mathrm{cm}^{2}$. Longer exposure in the solution did not cause significant changes in resistance. In fact, the transient electrical resistance decreased to $107 \mathrm{Ohm} \cdot \mathrm{cm}^{2}$ after 65 days of testing [37]. Application of cathodic potential improved the anticorrosive properties of the highly elastic epoxy coating in question, since the transient electrical resistance of the coating under cathodic polarization was significantly higher than without polarization and amounted to $\sim 10^{9} \mathrm{Ohm} \cdot \mathrm{cm}^{2}$ for more than 35 days of testing in the chloride-containing electrolyte. According to [37], the results indicate that an applied cathodic potential nearly does not affect the barrier properties of the epoxy coating. However, the authors believe that, in fact, the barrier properties of the coating are improved under applied cathodic potential. It is interesting that once the cathodic polarization is turned off, the transient electrical resistance of the coating immediately drops by an order of magnitude to $10^{8} \mathrm{Ohm} \cdot \mathrm{cm}^{2}$, which confirms the role of applied cathodic potential in improving the coating's barrier properties. It was reported [41] that the impedance modulus of epoxy-polyamide coatings $250 \mu \mathrm{m}$ thick immersed in sea water for 120 days decreased under cathodic protection due 
to a cathodic reaction at the metal-coating interface. Similar observations were reported [42] for epoxy coatings on steel.

To clarify the reasons for the decrease in the coating resistance after the cathodic protection is turned off, the Nyquist plots obtained during testing of steel samples with an epoxy coating in 3.5\% NaCl solution were analyzed [37]. The Nyquist plots both in the presence and in the absence of cathodic polarization had the shape of a single semicircle, indicating that the coating was intact and there was no sign of corrosion at the interface. When the coating is continuously immersed in water or $3.5 \% \mathrm{NaCl}$, the diameter of the semicircle on the Nyquist plot decreases with an increase in exposure time due to gradual water penetration through the coating to the metal surface. Moreover, a decrease in impedance was observed in the Nyquist plot after cathodic polarization was turned off. However, after the polarization was turned off, the resistance was still in the same range as that of the coated sample in the absence of cathodic polarization (i.e., under free corrosion conditions). It is believed [37] that the resistance $\left(R_{\mathrm{c}}\right)$ determined by electrochemical impedance spectroscopy, which changes when a cathodic potential is applied, is the resistance of the coating, since all Nyquist plots were better described by a Randle-type equivalent circuit. At the end of the tests, after 35 days, $R_{\mathrm{c}}$ decreases by an order of magnitude while the coating capacity increases. Unfortunately, the authors failed to identify the exact reason for the decrease in the coating resistance after the cathodic polarization is turned off [1].

It was observed in a study on the effect of the coating thickness on the cathodic delamination [38] that after 28 days of testing at $65^{\circ} \mathrm{C}$, the cathodic current responsible for the coating delamination decreased twofold at a coating thickness of 900-1000 $\mu \mathrm{m}$ and threefold at a thickness of $500 \mu \mathrm{m}$. A study on the effect of potential showed that a $1400 \mu \mathrm{m}$ thick coating delaminated by $1 \mathrm{~mm}$ at a potential of $-1.5 \mathrm{~V}$ and by $6 \mathrm{~mm}$ at $-3 \mathrm{~V}$ at equal test times and concentrations of the sodium chloride solution [38].

Yet another important factor affecting the cathodic delamination of coatings is noted [38], namely, a decrease in the coating thickness under chemical attack by the products of the electrochemical processes that occur on the electrodes under cathodic protection, namely, by chlorate ions formed at the anode. When electric current is passed through an electrochemical cell, sodium chloride is converted to sodium chlorate that is more chemically corrosive (reactions 4-7), and at a current of $50 \mathrm{~mA}, 1.3 \mathrm{~g}$ of sodium chloride is converted in $24 \mathrm{~h}$ to $1.65 \mathrm{~g}$ of sodium chlorate [38]. The chlorate ion chemically reacts with the polymer coating, dissolving the top layer that is in contact with the test solution. This decreases the coating thickness and thereby increases the liability of the coating to cathodic delamination [38].

$$
\begin{gathered}
2 \mathrm{H}_{2} \mathrm{O}+2 e^{-} \rightarrow 2 \mathrm{OH}^{-}+\mathrm{H}_{2} \\
2 \mathrm{Cl}^{-} \rightarrow 2 \mathrm{Cl}+2 e^{-} \\
2 \mathrm{Cl}+2 \mathrm{OH}^{-} \rightarrow \mathrm{Cl}^{-}+\mathrm{ClO}^{-}+\mathrm{H}_{2} \mathrm{O} \\
2 \mathrm{Cl} \rightarrow \mathrm{Cl}_{2}
\end{gathered}
$$


However, tests of steel samples coated with an epoxy coating $900 \mu \mathrm{m}$ thick showed no significant differences between tests with insulated and non-insulated anodic space at a potential of $-1.5 \mathrm{~V}$, a temperature of $65^{\circ} \mathrm{C}$ and a test duration of 28 days [43]. The delamination zone was $3 \mathrm{~mm}$ in one case and $16 \mathrm{~mm}$ in the second case. However, it is stated [38] that the resulting delamination rate is directly proportional to the concentration of chlorate in the electrolyte, and therefore, isolation of the anodic space or frequent renewal (refreshing) of the electrolyte are recommended to prevent the cathodic delamination of coatings.

In addition to the above, the same authors [38] state that the delamination rate (in $\mathrm{mm}$ /day) is directly proportional to the temperature. Higher temperatures result in the expansion of the delaminated area after an increase in current. The typical current on the first day of testing measured at $65^{\circ} \mathrm{C}$ is almost two times higher than the current at $23^{\circ} \mathrm{C}$. As a result, a proportional growth of the cathodic delamination zone was observed [38]. For example, no delamination was observed at $23^{\circ} \mathrm{C}$ at a mean sodium chlorate concentration of $1 \mathrm{~g} / \mathrm{l}$. At the same time, on heating the electrolyte to $65^{\circ} \mathrm{C}$ at the same concentration of chlorate, coating delamination was observed on $\sim 40 \%$ of the specimen area [38]. This effect of temperature was explained by the fact that an elevated temperature caused a higher water vapor pressure and increased the penetration of water vapor through the coating, while the porosity of the coating increased due to chemical attack and thermal expansion [38].

An increase in temperature above the glass transition temperature of the polymer (coating base) strongly affects the resistance of the coating to cathodic delamination. The other parameters, such as the electrolyte composition and the applied cathodic potential, increase the rate of cathodic delamination in tests at higher temperatures [38].

It is stated [38] that the voltage is the main parameter in tests of coating resistance to cathodic delamination. A low-voltage test better simulates field conditions but requires longer test times, whereas at higher voltages, a shorter test time is sufficient but the field conditions are simulated less reliably [38].

In $[44,45]$, water capable of diffusing through a coating to the metal surface was considered as one of the important factors affecting both the liability of a coating to cathodic delamination and the metal corrosion under the coating. The suggested efficient method for reducing the liability to cathodic delamination and inhibition of metal underfilm corrosion is to introduce a filler capable of hydrogen bonding of mobile water, thus preventing its migration to the metal-polymer interface. Chemically modified multiwalled carbon nanotubes (CNTs) are suggested as such a filler [44]. The CNTs were modified to hydroxylate the nanotube surface by forming a hydroxyl layer on it capable of hydrogenbonding mobile water, thus preventing its migration into the polymer bulk to the metal surface and its participation in the cathodic reaction at the interface. Accelerated corrosion tests of steel samples with an epoxy-amine coating with addition of three different concentrations of CNTs showed that modified nanotubes affected the distribution of free and hydrogen-bound water in the coating, which subsequently decreased the rate of both cathodic 
and corrosion-related delamination of the coating and reduced the corrosion rate of steel by $\sim 25 \%$ in salt spray chamber tests [44].

It was shown in [44] how water-hydrogen bonds are distributed in the coating. This distribution is believed to be the reason for the change in the rate of cathodic delamination due to a reduced mobility of ions at the coating/substrate interface, as well as a decrease in the transport rate of water-solvated ions - components of poorly water-soluble pigments that can slow down anodic reactions and/or re-polarize the cathodic surface areas, thus reducing their anti-corrosion efficiency [45]. Estimation of the mechanistic interaction of water hydrogen bonds during the delivery of these corrosion-inhibiting particles to the sites of corrosion reactions made it possible to develop a model that includes equations for predicting the rates of coating delamination and metal corrosion. The correlations found in [44] were qualitatively checked by determining the dependence of the amount of side products of metal corrosion at the polymer/substrate interface on the relative concentration of free water in the coating. Stepwise multivariate regression analysis gave an equation capable of predicting the delamination rates in $91 \%$ cases of cathodic delamination using the relative content of free and weakly bound water in the polymer measured before the analysis as a single variable. It was found [44] that the rate of cathodic delamination and corrosion of coated steel substrates with macroscopic defects is mechanically related to interactions in the polymer involving hydrogen bonds that determine the rate of ion transfer through the polymer to the metal surface. Other factors such as thickness, pigment volume concentration, polymer chemistry, cross-linking density, adhesion, and presence of other additives can also affect the overall characteristics of underfilm corrosion $[44,46]$. The results of studies on the interaction of water-hydrogen bonds and the possibility of predicting the overall rates of delamination and corrosion under intact coatings made it possible to assume that controlling the hydrogen bonding of water within a coating would control the diffusion of ions and the rate of metal underfilm corrosion [45].

In $[39,47]$, the factors affecting the cathodic delamination of epoxy coatings on steel were studied. It was found that the delamination rate decreased linearly with an increase in the thickness of the dry film and depended on the type of cation in the electrolyte. The assumption was made that the transport route for electrolyte cations passed through the already delaminated part of the coating. In [48], the cathodic delamination of chlorinated varnish coatings on steel under free corrosion conditions in solutions of alkali metal chlorides was studied. Measurements of the delamination rate of a non-pigmented varnish showed that it largely depended on the mobility of cations. A parabolic dependence was observed, whereas no such dependence was found for the same coating with a pigment $[47,49]$. Thus, it was hypothesized that the rate-determining process for delamination varied from ion transport along the interface in the absence of a pigment in the coating to oxygen diffusion through the same path upon pigment addition [49]. In [48, 50], where the effect of various factors on the cathodic delamination of epoxy coatings was studied, it was found that the cathodic delamination zone increased on replacement of air with pure oxygen. Increasing the concentration of potassium cations to a certain value also intensified delamination. 
Moreover, it is assumed $[48,51]$ that the effect of ion concentration on the solubility of dissolved oxygen is more important than the concentration of ions, and the rates begin to decrease when oxygen diffusion become the rate-determining process, as suggested in [47]. The cathodic delamination rate increased linearly with applied potential. In addition, it was shown [51,52] that an increase in the pigment concentration and a decrease in the amide/epoxy ratio in an epoxy resin reduces the rate of cathodic delamination. Tests were carried out $[48,49,51]$ where a layer of aluminum foil was placed around a coating defect, which blocked the transport of all particles through the intact coating. As a result, a sharp decrease in the delamination rate was observed, which was explained by a dependence of the delamination rate on the transfer of water and oxygen through the coating $[49,51]$. Though the delamination indicators linearly decreased with an increase in the coating thickness, an inverse proportional plot of the delamination rate $v s$. coating thickness was not obtained [48].

A study on the effect of film thickness on delamination [48] showed the importance of processes occurring in the coating through pores. These processes are accelerated with a decrease in the coating thickness. If the transport of external medium components was the rate-determining process, then an inversely proportional relationship between the delamination rate and thickness was observed in the thickness range from 5 to $10 \mu \mathrm{m}$ [48]. Moreover, a linear relationship (with a correlation coefficient of 0.99 ) was obtained between the square of the displacement of the delamination front and the test time, which indicates that there is a parabolic relationship at coating thicknesses from 5 to $10 \mu \mathrm{m}$ [48].

Measurements of the delamination rates on steel samples with an epoxy coating having various film thicknesses showed that a threefold increase in the coating thickness caused only a slight decrease in the delamination rate [48]. Similar results were also obtained elsewhere $[39,52,53]$, although a linear dependence of the rate of thickness decrease of very thick coatings was only observed after long testing periods [53]. On the other hand, it was reported [5] that the delamination rate of an alkyd coating dropped to very low values when the top coating thickness exceeded $90 \mu \mathrm{m}$, but in tests in $0.5 \mathrm{M} \mathrm{NaCl}$ solution at a cathodic potential of $-0.8 \mathrm{~V}$, the delamination rate of the primer with a top coating changed insignificantly at coating thicknesses exceeding $50 \mu \mathrm{m}[5,48]$.

It is believed [48] that if the reactions at the coating/metal interface or along it totally determine the delamination rate, then the film thickness should not affect the delamination rate at all; however, in practice, some effect is observed. In fact, it was shown [51] by blocking the transport with an aluminum foil, which nearly stopped delamination, that the transfer of water (or oxygen) through the coating plays a certain role, which agrees with the rate decrease with an increase in thickness observed in [48]. Similarly, it was shown that addition of a flaky (i.e., consisting of flake-shaped particles) pigment into a coating decreased the permeability and decreased the rate [48], which implies the diffusion control of delamination determined by the through transport of environment components, at least in thick coatings [48]. 
In studies on the effect of the electrolyte nature on cathodic delamination, tests were carried out to estimate the change in the exfoliation area versus time in $0.5 \mathrm{M} \mathrm{LiCl}, \mathrm{NaCl}$, $\mathrm{KCl}$, and $\mathrm{CsCl}$ solutions [53]. As a result, the effect of the nature of electrolyte cations on the delamination rate was determined. For example, it was found that the delamination of the coating in a $\mathrm{KCl}$ solution occurred more quickly than in $\mathrm{CsCl}$. The results made it possible to arrange the cations by their effect on the delamination rate in the following series [48]: $\mathrm{K}^{+}>\mathrm{Cs}^{+}>\mathrm{Na}^{+}>\mathrm{Li}^{+}$. This result was unexpected [48] since the results of other studies [1, 5, 52] gave a different series, $\mathrm{Cs}^{+}>\mathrm{K}^{+}>\mathrm{Na}^{+}>\mathrm{Li}^{+}$, which agreed with the data on the mobility of these ions in aqueous electrolytes [48]. It is believed [54] that there is a trend towards faster delamination in electrolytes with more mobile cations. Based on an analysis of the linear dependence of the delamination rate on electrolyte concentration for $\mathrm{LiCl}, \mathrm{NaCl}$ and $\mathrm{CsCl}$, the critical cation mobility required for delamination was found to be $2.8 \cdot 10^{8} \mathrm{~m}^{2} \cdot \mathrm{s}^{-1} \cdot \mathrm{V}^{-1}$ [48].

A study on the effect of electrolyte concentration showed a linear relationship between the coating delamination rate constant and the solution concentration at $\mathrm{NaCl}$ concentrations above 1 wt. \% [48]. High scatter of results was observed in dilute solutions with concentrations of $0.1 \%$ or lower, which made the analysis difficult [48]. The authors considered two possible factors causing an increase in the delamination rate with an increase in solution concentration and found that with an increase in solution conductivity, the current passing along the metal-polymer interface increases, whereas the potential difference between the metal at the tip and mouth of the coating delamination region decreases. In this case, a more negative potential is observed at the point where delamination occurs, which indicates that the cathodic reaction rate accelerates there [48]. The intensification of the cathodic process favors the formation of a higher concentration of an alkali (or free radicals), which accelerates the coating delamination from the metal. However, it should be borne in mind that the alkaline solution near the delamination tip is actually more concentrated than the majority of test solutions [17]. It was reported [55] that the concentration of cations significantly affected the delamination rate, while at a concentration of cations below $0.5 \mathrm{M}$, no delamination was recorded. This observation was explained by the fact that this is the minimum concentration of ions at the coating/metal interface required to establish a "galvanic cell". SKP measurements show that potential gradients exist under a coating $[55,56]$. It is stated [57] that electro migration of ions is more important than their diffusion; therefore, the electric field strength in the coating delamination zone is important. It was suggested $[36,58]$ that the potential difference between the delamination tip and the undamaged interface in front of it controls the delamination rate.

When a coated metal sample is polarized at sufficiently cathodic potentials, the metal in the defect is cathodically protected and its corrosion dissolution is prevented, while the rate of the cathodic reaction under the coating increases and is no longer limited by the rate of the anodic dissolution of the metal in the defect [48], like under free corrosion conditions. This results in stronger delamination [47].

A study on the behavior of a metal in a polymer coating defect showed [48] that the free corrosion potential decreased rapidly in the first 2000 seconds of testing and continued 
to decrease in the first day, after which it stabilized and remained invariable and even increased somewhat. The potential drop corresponds to the onset of corrosion. Therefore, during the initial test period, cathodic polarization under the coating is not intense enough to cause its delamination. A small subsequent increase in potential (by $28 \pm 5 \mathrm{mV}$ ) has a minor effect on the delamination rate [48].

Furthermore, a study on the effect of temperature on the cathodic delamination showed [48] that delamination of an epoxy coating from steel at $30^{\circ} \mathrm{C}$ occurred more quickly than at $22^{\circ} \mathrm{C}$. The induction period of delamination (i.e., the time until the beginning of delamination) also became shorter with a decrease in temperature from 30 to $22^{\circ} \mathrm{C}$. At higher temperatures $\left(40^{\circ} \mathrm{C}\right.$ and $\left.50^{\circ} \mathrm{C}\right)$, a similar behavior was observed. In fact, after the first three days of testing at $50^{\circ} \mathrm{C}$, the coating delaminated from the entire sample surface. At $40^{\circ} \mathrm{C}$, the delamination rate was much weaker and the coating delaminated on only $40 \%$ of the sample surface. It is believed [48] that if delamination is controlled by a thermally activated process such as ion diffusion, then the dependence of the cathodic delamination rate on temperature should be described by the Arrhenius equation (Equation 8) that characterizes the activation energy $\left(E_{\mathrm{a}}\right)$, provided that the same process that controls the rate is operative in the entire temperature range.

$$
k=A e^{-E_{\mathrm{a}} / R T}
$$

From the results obtained at $22^{\circ} \mathrm{C}$ and $30^{\circ} \mathrm{C}$, the estimated $E_{\mathrm{a}}$ of coating delamination was calculated to be $10.1 \mathrm{~kJ} / \mathrm{mol}$ [48]. The authors believe that if this value corresponds to the activation energy of transport under the coating, then it is smaller than for ions in the intact polymer (27-30 kJ/mol [81]) but just slightly higher than that of transport in solution $(7.9 \mathrm{~kJ} / \mathrm{mol}[82])$. A sudden increase in the rate with temperature was expected on reaching the glass transition temperature of the polymer [48]. The activation energy of ionic conductivity drops sharply on reaching the glass transition temperature of the polymer [48], which results in a faster decrease in the coating resistance with temperature. Studies using electrochemical impedance spectroscopy have shown that the coating resistance drops sharply at temperatures above $T_{\mathrm{c}}$ due to the rapidly increasing free volume [48].

A study on the cathodic delamination of a coating with semi-immersion of a coated sample into a solution showed that the delamination rates under the semi-immersion conditions were similar both above and below the waterline, as shown in [59]. According to [48], this convincingly indicates that all important processes associated with cathodic delamination occur along the interface under a coating, and if water vapor and oxygen have access to the coating surface, delamination above the solution level does not depend on the lack of contact with the solution. However, it was found in the case of pigmented coatings under semi-immersion conditions that a parabolic kinetics better describes the process than a linear kinetics, both above and below the water level, as opposed to the linear dependence obtained for totally immersed samples [48]. 
A linear time dependence of cathodic delamination for an epoxy primer on a steel substrate with different roughness was reported [60]. It is consistent with the kinetics of linear cathodic delamination observed [48] for pigmented epoxy coatings.

The tests carried out in [61] showed that ions migrated both along the interface and through the coating. If a pigment favors the transportation of ions through a coating as suggested in [52], then, according to [48], this can explain the change in the linear kinetics but should increase the delamination rate. Moreover, in was expected [48] that in the case of semi-immersion, the delamination kinetics below the waterline would be the same as in the case of full immersion, but the process would occur more slowly than above the waterline. However, this was not observed and hence it was assumed [48] that tests with pigmented coatings apparently show a different kinetics that depends on the mode of exposure and therefore the results differ from the full immersion mode. Furthermore, studies by scanning acoustic microscopy have shown [48] that the pattern of blistering on pigmented coatings is different than on non-pigmented ones, which may be the reason for the different kinetics in these two cases.

\section{Methods for inhibiting the cathodic delamination of coatings}

As a rule, nearly all researchers who study the cathodic delamination of polymer coatings from metals suggest methods for inhibiting the delamination based mainly on changes in those factors or characteristics that the researcher studied. In some published papers, versatile methods for minimizing the cathodic delamination are suggested. For example, it was noted back in the 80s of the 20th century [5] that the surfaces of many industrial painted metal structures are specially treated to minimize cathodic delamination before a coating is applied. The metal surface is chemically modified by a process known as "pretreatment" or "finishing". The pretreatment methods are usually based on the use of pretreatment formulations containing phosphates, silicates, and chromates. However, the changes in environmental, financial and other requirements led to continuous changes in the technological approaches to surface pretreatment processes [5]. Therefore, no efficient and reliable method has been suggested to date for preventing the cathodic delamination of coatings from metals. In [5], attempts were made to describe those characteristics of the interfacial region at the organic coating/metal interface which, in the authors' opinion, are capable of minimizing cathodic delamination. In particular, the following characteristics of the interface were emphasized:

1. No pure metal or surface-oxidized metal should be present at the coating/substrate interface. Weakly oxidized metals such as copper, zinc and steel are good catalysts of the oxygen reduction reaction. Since the hydroxyl ion is a destructive component in the separation process, the formation rate of these ions should be minimized. Any layer on the metal surface should completely cover the metal and thus limit the access of reagents to the metal surface. 
2. A layer that is a very poor conductor of electrons should be present at the coating/substrate interface. The electrons for the cathodic reaction are provided either by an external power supply or by the anodic half of the corrosion process. If the supply of electrons to the interface can be minimized, the reaction rate will decrease. A non-metallic interface layer with poor electron conductive properties is desirable.

3 . The layer at the coating/substrate interface should be a poor catalyst of the cathodic reaction. In fact, two common cathodic reactions (either occurring at the interface $(9,10)$ or one overall (11)) do not readily occur in the absence of a solid compound [5].

$$
\begin{gathered}
\mathrm{H}_{2} \mathrm{O}+\frac{1}{2} \mathrm{O}_{2}+2 e^{-}=2 \mathrm{OH}^{-} \\
2 \mathrm{H}^{+}+2 \mathrm{e}^{-}=\mathrm{H}_{2} \\
\mathrm{O}_{2}+4 \mathrm{H}_{2} \mathrm{O}+6 e^{-} \rightarrow \mathrm{H}_{2}+6 \mathrm{OH}^{-}
\end{gathered}
$$

The first reaction (Equation 9) most readily occurs on oxidized metals, while the second one (Equation 10), on bare metal surfaces. As a result of all cathodic reactions, a local increase in $\mathrm{pH}$ occurs, which plays an important role in cathodic delamination, as noted above. It is observed [5] that the relative importance of each reaction depends both on the potential and on the nature of the surface.

4. The interface between the substrate and the coating should be uneven (rough). It is common practice to improve the adhesion of a substrate to an organic coating by increasing the surface roughness, either by abrasion or chemical attack, and/or by the formation of reaction products (e.g., corrosion products) with a large surface area. A rough surface is believed to have yet another valuable property for inhibiting the cathodic delamination: roughness provides a more sinuous path for the diffusion of cations to the place of formation of hydroxyl ions that often play a decisive role in the destruction of interface bonds that results in the loss of adhesion and, hence, in delamination. The main ingredients of the oxygen reduction reaction include (a) water, (b) oxygen, (c) electrons, (d) a catalytically active surface, and (e) cations to provide electro neutrality for hydroxyl ions. It was shown [5] that in some systems, the cathodic delamination in $\mathrm{NaCl}$ solution occurs due to "lateral" diffusion (i.e., not through the coating but along the interface) of sodium cations under the coating. Any surface structure that makes the diffusion path of cations longer or hinders their migration to locations of possible formation of hydroxyl ions would reduce the oxygen reduction rate [5].

5. The interface region should be resistant to alkaline attack. The delamination process occurs due to attack of the surface oxide by hydroxyl ions or, as noted above, the organic coating near the interface or metal-polymer interface bonds is attacked by hydroxyl ions. An ideal interface would include an alkali-resistant coating on the metal and an organic material that is highly resistant to hydrolysis or other type of attack with aqueous alkali [5]. 
It is believed $[2,62]$ that the coating delamination rate would decrease with an increase in the coating thickness and adhesion, as well as upon deposition of layers that inhibit the cathodic reduction of oxygen onto the interface surface $[2,5,62]$.

In [60, 63-67], the effect of metal surface treatment before applying a coating on the coating resistance to cathodic delamination was studied in detail. As shown in [60], the cathodic delamination of epoxy coatings in neutral $0.5 \mathrm{M} \mathrm{Na}_{2} \mathrm{SO}_{4}$ solution occurred much more slowly from steel surfaces pretreated with hexafluorozirconic acid than from untreated steel. This was attributed [60] to an increase in the coating adhesion upon surface treatment, because a longer surface pretreatment significantly increased the slower cathodic delamination of epoxy coatings in a neutral solution. Moreover, it was shown that surface pretreatment with hexafluorozirconic acid decreased the rate of cathodic delamination not only in neutral but also in acid electrolytes [60]. Electrochemical studies (electrochemical impedance spectroscopy, potentiodynamic methods) on the effect of surface treatment with hexafluorozirconic acid on the corrosion resistance of steel showed that corrosion inhibition occurred. Moreover, an increase in the surface treatment time caused a proportional increase in corrosion resistance that was attributed to the formation of a denser and more ordered $\mathrm{ZrO}_{2}$ layer with an increase in the time of steel surface treatment with a hexofluorozirconic acid solution [60]. It was shown in a study on the effect of steel surface treatment with a solution containing $\mathrm{Ce}^{2+}$ salts on the adhesion properties of epoxy coatings and the corrosion characteristics of steel [63] that, in comparison with acid washing, chemical treatment with a cerium-containing solution resulted in a noticeable increase in the free surface energy of steel, improvement of adhesion properties, including a decrease in the rate of cathodic delamination (according to the results of tests in accordance with [24]) of an epoxy resin, and an increase in the corrosion resistance of the metal under the coating. It was shown that cerium compounds reduced the cathodic activity of the steel substrate and favored the inhibition of coating delamination in an alkaline medium, despite the fact that the adhesion of the epoxy coating was lower on the sample treated with a cerium-containing solution than on the sample treated with an acid [63].

In [64], a steel surface was treated with red clay before applying a polymer coating. It was shown that this treatment effectively prevented the coating delamination from cathodically protected painted steel plates immersed in chloride-containing solutions.

In [65], chromium-metal-oxide-carbide coatings with various compositions and thicknesses obtained on a steel surface by cathodic electrodeposition from an electrolyte containing $\mathrm{Cr}$ (III) compounds were studied and compared in terms of their ability to prevent the corrosion-initiated delamination of a polymer coating. The rates of cathodic delamination were determined using an "in situ" scanning Kelvin probe (SKP). It was shown that the rate of corrosion-initiated delamination of a model polyvinylbutyral (PVB) coating decreased with an increase in the content of chromium(III) oxide in the treating electrolyte and in the total thickness of the $\mathrm{Cr}$ (III)-based coating. Thick $\mathrm{Cr}$ (III) coatings containing a sufficient amount of $\mathrm{Cr}$ (III) oxide coating were found to prevent corrosion and corrosion-induced delamination of organic coatings. Moreover, coatings based on trivalent chromium have 
characteristics comparable to those based on hexavalent chromium that provide higher adhesion and anticorrosion properties of the metal surface but do not meet modern environmental requirements [68].

It was shown that the kinetics of cathodic delamination from iron at small thicknesses of a conversion coating containing $\mathrm{Cr}$ (III) was limited by the migration rate of $\mathrm{Na}^{+}$cations and had a parabolic shape. At the same time, a transition from parabolic kinetics to zeroorder linear kinetics was observed for steel samples with a thicker coating [65]. Moreover, lower currents of cathodic oxygen reduction determined by polarization methods were observed for samples with a Cr(III) conversion coating compared to "pure" steel without pretreatment. The authors showed that the oxygen reduction reaction (ORR) with participation of 2 electrons (Equation 12) occurs predominantly on an oxide-coated chromium surface, whereas the ORR involving 4 electrons (reaction 13) occurs on a "bare iron" surface that is not coated with either a chromate conversion coating or iron oxide [65]:

$$
\begin{gathered}
\mathrm{O}_{2}+2 e^{-}+2 \mathrm{H}_{2} \mathrm{O} \rightarrow 2 \mathrm{OH}^{-}+\mathrm{H}_{2} \mathrm{O}_{2} \\
\mathrm{O}_{2}+2 \mathrm{H}_{2} \mathrm{O}+4 e^{-} \rightarrow 4 \mathrm{OH}^{-}
\end{gathered}
$$

In [66], a number of methods were used to estimate the effect of various types of steel surface pretreatment on the wet and dry adhesion of an alkyd coating, corrosion resistance of a metal, and resistance of the alkyd coating to cathodic delamination from steel. It was found that, though some treatments significantly improved the adhesion while others significantly increased the resistance to corrosion and/or cathodic delamination, these phenomena were not related [66]. For example, situations were encountered where a significant decrease in corrosion resistance was observed along with improved wet and dry adhesion. Opposite situations were also encountered where some types of surface pretreatment improved both the anticorrosive and adhesive characteristics [66]. For example, it was shown that phosphatization reduced the adhesion but greatly increases the resistance both to corrosion and, especially, to cathodic delamination. Abrasive blasting of the surface did not affect adhesion but impaired the corrosion resistance, according to the authors, due to insufficient filling of the defects of the more developed surface (more developed profile after abrasive surface treatment) with the alkyd coating. On the other hand, the resistance to cathodic delamination improved [66]. Surface treatment with a chromate-containing electrolyte and application of chromate conversion coatings improved the adhesive properties of alkyd coatings, increased the corrosion resistance of the metal, and increased the resistance of the alkyd coating to cathodic delamination [66].

One would expect that an increase in the strength of the metal-polymer adhesive bond would also increase the resistance of the coating to cathodic delamination. In some cases, this is confirmed by the reported experimental data [66] (see above). Special compounds, so-called adhesion promoters (or "coupling agents"), are often used to increase the adhesion of polymer coatings to metals. Organosilanes $\mathrm{R}_{n} \mathrm{Si}\left(\mathrm{OR}^{\prime}\right)_{4-n}$ are among compounds most frequently encountered in literature as adhesion promoters [69-71]. They are adsorbed on 
metal surfaces to form self-organizing siloxane surface nanolayers by interaction with hydroxyl groups on the surface. In addition, they can interact with components of the polymer coating via organic radical $\mathrm{R}$ in a molecule. Thus, owing to the bifunctionality of organosilane molecules, they can form strong bonds with a surface and with a polymer coating to improve adhesion. Therefore, an increase in the resistance to cathodic delamination could be expected upon application of an organosilane layer on a metalpolymer interface. Indeed, this effect was observed in [67] where a significant increase in the stability of siloxane and polybutadiene anticorrosive coatings under cathodic polarization was shown. This is explained by an increase in adhesion at the metal-polymer interface and a decrease in hydrolysis rate of the surface iron oxide [67]. On the other hand, it was found [72] that pretreatment of a steel substrate with a solution of 3-glycidoxypropyltrimethoxysilane (3-GPS) increased the dry and wet adhesion of an epoxy coating. Likewise, pretreatment with a 3-aminopropyltriethoxysilane (3-APS) solution favored the dry and wet adhesion of alkyd coatings. Nevertheless, although pretreatment with 3-GPS reduced 3-fold the cathodic delamination rate of an epoxy resin, surface treatment with a 3-APS solution did not show an increase in the resistance of the alkyd coating to cathodic delamination, even though such treatment increased the coating adhesion to steel [72]. It was found [66] that surface silanization significantly improved the adhesion in both wet and dry states but reduced the corrosion resistance without significantly affecting the cathodic delamination rate [66].

In [73], steel substrates were treated by solutions of silanes additionally containing functionalized nanoplates (nanosheets) of graphene oxide (fGO) to give silane surface layers (films), both without a filling and filled with 0.1 mass $\%$ fGO. The results showed that incorporation of fGO into a silane film decreased the contact wetting angle and increased the work of adhesion. The silane composite film efficiently increased the bond strength between the epoxy coating and the steel surface. The silane (3-APS-based) composite film filled with fGO nanosheets significantly improved the adhesion properties of the epoxy coating in a corrosive electrolyte. Moreover, it was found that fGO significantly reduced the delamination rate of an epoxy coating on a steel substrate pretreated with an organosilane solution [73].

In addition to the treatment of metal surfaces, attempts are made to increase the resistance of coatings to cathodic delamination by modification of polymer coatings, i.e., by incorporation of modifying additives, such as pigments, adhesion promoters, corrosion inhibitors, etc., to the polymer bulk [74-79]. In [75], coatings were modified by addition of azole-containing compounds to the polymer bulk. In some cases, these compounds are capable of inhibiting the corrosion of metals [80]. The cathodic delamination of epoxy coatings from mild steel was studied in $3.5 \% \mathrm{NaCl}$ solution. Benzimidazole, benzothiazole, and benzotriazole were used as modifying additives in the coatings. The results showed that azole compounds were not immobilized in the coatings, since they could be washed out and acted as cathodic inhibitors at the defect sites and at the coating delamination front [75]. It was found that addition of organic azole-containing corrosion inhibitors to an epoxy coating 
increased the resistance of the coating to cathodic delamination. It was also shown that an increase in the adhesion strength of the coating in the wet state in the presence of azole compounds could cause an increase in the resistance of the coating to cathodic delamination. The authors of [75] believe that this is not the dominant mechanism of action of azole compounds in reducing the cathodic delamination. They believe that the main mechanisms of action of azole compounds in increasing the resistance to cathodic delamination include (1) an increase in the charge transfer resistance and a decrease in the cathodic reaction rate due to adsorption of inhibitors on the metal surface and (2) an increase in the glass transition temperature of coatings that decreases the permeability of coatings to water and oxygen. In addition, as noted above, the modifying azole compounds are not bound strongly enough to the coating and can be reached out and act as cathodic inhibitors at coating defects and at the delamination front [75]. In [76], an anticorrosive zinc-free pigment based on strontiumaluminum polyphosphate (PPSA) was suggested as a modifier. The predominant effect of coating modification (by introducing PPSA into its bulk) on the characteristics of cathodic delamination of an epoxy polyamide coating was studied. It was shown that, irrespective of the applied potential, the presence of PPSA in the coating caused a slower growth in the exfoliation area compared with a zinc-containing pigment. According to the data obtained using electrochemical impedance spectroscopy (EIS) and scanning electron microscopy equipped with energy dispersive X-ray spectroscopy (SEM-EMF), this behavior was explained by the locally controlled $\mathrm{pH}$ and the deposited film that limited the active zones available for electrochemical reactions [76]. Moreover, EIS measurements confirmed that replacement of the zinc-containing pigment with zinc-free PPSA reduced the cathodic delamination [76].

In [77], the protective properties and cathodic delamination of an epoxy coating pigmented with zinc aluminum phosphate (ZAP) were studied. On addition to a solution, ZAP showed more efficient corrosion inhibition than zinc phosphate (ZP). The deposition of a protective layer responsible for the inhibitory behavior was detected on the metal surface. Using EIS and the electrochemical noise analysis method, it was found that ZAP efficiently inhibited metal corrosion due to deposition of a protective layer on the surface [77]. Estimation of the behavior of pigmented epoxy coatings by EIS showed a significant effect of modification of a ZP coating on its anticorrosive characteristics and on its resistance to cathodic delamination. In comparison to ZAP, zinc phosphate reduced the coating resistance to cathodic delamination. EIS and SEM detected a deposit near the coating delamination front in the presence of ZAP. It was found that the resistance to cathodic delamination strongly depended on the type of pigment. Compared to ZAP, incorporation of $\mathrm{ZP}$ into an epoxy coating resulted in an increase in the delamination area. In the case of ZAP, inhibition of cathodic delamination was due to the deposition of a protective layer and the controlled $\mathrm{pH}$ under the coating [101].

It was shown [78] that inexpensive and environmentally friendly cation exchange pigments obtained from natural bentonite clay significantly increased the resistance to corrosion- stimulated/cathodic delamination of organic coatings from iron surfaces. The 
kinetics of delamination of pigmented and non-pigmented coatings based on polyvinylbutyral (PVB) deposited on polished iron substrates was studied. It was shown by SZK that pigments based on bentonite clay are the most efficient. They have cation-exchange properties and can exchange the following cations: $\mathrm{Ca}^{2+}, \mathrm{Sr}^{2+}, \mathrm{Ba}^{2+}, \mathrm{Mg}^{2+}$, and $\mathrm{Ce}^{3+}$. The dependence of the coating delamination rate on the volume fraction of a $\mathrm{Ca}^{2+}$-containing bentonite pigment was determined. It was shown that it was comparable to that of the commonly used pigment containing strontium chromate $\left(\mathrm{SrCrO}_{4}\right)$ and $\mathrm{Y}^{3+}$, while addition of a bentonite pigment to the coating significantly increased the coating resistance to corrosionstimulated delamination from iron and steel surfaces [78]. It was shown that for all cationexchange bentonites, the rate of coating delamination progressively decreased with an increase in the pigment volume fraction. Nevertheless, it was found [78] that the kinetics of exfoliation was determined by the migration of cations under the film, even despite the inhibition of delamination. However, the authors did not observe any inhibition of filiform corrosion that can also cause the coating delamination [78].

Modification of a bitumen-polymer coating with adhesion promoters, i.e., addition of amino-(3-APS) and vinyl-containing (VS) triethoxysilanes into the polymer bulk, showed that modification of the coating by addition of 3-APS nearly does not affect its liability to cathodic delamination. Vinylsilane added to a coating inhibited the cathodic delamination due to a better compatibility of the vinyl radical with the components of the bitumenpolymer coating [79].

A study on the effect of coating modification by introducing graphene oxide (GO) nanoplates (nanosheets) into the bulk of a polymer and especially covalent functionalization of the GO surface with diamine-containing compounds (pGO preparation) on the barrier and anticorrosive properties of an epoxy coating showed [81] that the amino functionalization of GO was successfully performed due to a covalent interaction between the carboxy and epoxy groups of GO and the amine groups of the diamine. The GO surface became more hydrophobic after the functionalization. The interlayer distance of GO sheets increased significantly after the functionalization. fGO nanoplates were successfully embedded in the bulk of the epoxy coating (at a concentration of $0.1 \%$ ). Covalent bonding was observed between graphene oxide particles and epoxy coating components. The addition of fGO to the epoxy coating improved its barrier and anticorrosive characteristics [81]. The wear of the coating due to electrolyte diffusion into the coating matrix decreased significantly. Modification of the coating by fGO incorporation prevented the diffusion of $\mathrm{Cl}^{-}$ions into the coating bulk and a decrease in the basicity $(\mathrm{pH})$ at the metal-polymer interface due to interaction of fGO with hydroxyl ions [81], which resulted in an increase in the resistance to cathodic delamination.

In addition to the above methods for minimizing the cathodic delamination of coatings, other methods that might reduce the risk of cathodic delamination are available in literature. One of these methods is to use conductive coatings [82]. In particular, it was noted [83] that when a metal substrate with a conductive polymer coating was exposed to an electrolyte, galvanic coupling between the metal substrate and the electrolyte could arise due to the 
electronic conductivity of the internally conductive polymer (ICP). It was found that the metal oxidation [Equation 14] at the metal/ICP interface at the initial stage of exposure caused the reduction of the ICP [Equation 15], which decreased the passivating ability of the ICP film [83].

$$
\begin{gathered}
\mathrm{M} \rightarrow \mathrm{M}^{n+}+n e^{-} \\
\mathrm{ICP}^{n+}+n e^{-} \rightarrow \mathrm{ICP}^{0}
\end{gathered}
$$

In the case of insulating coatings, oxygen is reduced at the metal-ICP interface, which causes the delamination of organic coatings [83]. However, due to electronic conductivity, ICP can transfer electrons generated on the open surface into the coating. Thus, the presence of an ICP triggers the reduction of dissolved oxygen (Equation 16) at the ICP-electrolyte interface, which accelerates the reoxidation (Equation 17) of the ICP film.

$$
\begin{gathered}
n / 4 \mathrm{O}_{2}+n / 2 \mathrm{H}_{2} \mathrm{O}+n e^{-} \rightarrow n \mathrm{OH}^{-} \\
\mathrm{ICP}^{0} \rightarrow \mathrm{ICP}^{n+}+n e^{-}
\end{gathered}
$$

The displacement of the $\mathrm{O}_{2}$ reduction region slows down the cathodic delamination effect. A model study was carried out using a test for delamination of polypyrrole coatings (PPy) in an atmosphere containing isotopic oxygen $\left({ }^{18} \mathrm{O}_{2}\right)$ to determine the sites of dislocation of oxygen reduction [84]. The content of hydroxyl ions formed upon reduction of isotopic oxygen was determined by secondary ion mass spectrometry (SIMS). The results confirmed that the oxygen reduction sites shifted from the metal/ICP interface to the top of the conductive coating. It was shown that this effect was unfavorable for corrosion protection since a conductive polymer only transfers high concentrations of $\mathrm{OH}^{-}$ions from the $\mathrm{ICP} /$ metal interface to the upper part of the coating surface, thereby enhancing the delamination of the upper layer. The oxygen reduction site can be displaced into the bulk of the ICP film using ICP as pigments for modifying a non-conductive organic coating. Even in this case, the electrical conductivity of such systems can be sufficient to move the oxygen reduction site to the coating surface $[83,84]$. If larger defects are present, a conductive coating is unable to passivate the metal in such defects [83]. In this case, rapid reduction of the coating directly accompanied by delamination is observed. Since such reduction occurs more quickly than the usual delamination observed in the majority of non-conductive organic coatings, it is believed [83] that if large defects exist in a coating, conductive coatings stimulate rather than inhibit the delamination of coatings from metals. These two cases demonstrate why there are so many different opinions about the corrosion protection capabilities of conductive polymers. For example, it was found for a sample with a conductive polymer coating immersed in an electrolyte solution that the ability of conductive coatings to promote metal passivation in small defects results in high inhibitory efficiency with respect to metal corrosion and cathodic delamination compared to a conventional (non-conductive) organic coating. In the case of a large defect in the coating on the same sample, the efficiency of conductive coatings was lower than that of non-conductive ones. According to [83], this should apply to all coatings made of 
pure conductive redox polymers. However, if a conductive polymer is added as a modifier to an insulating coating, rapid reduction of the coating should be inhibited if the mean travel distance of conductive particles is not too long. Degradation of the insulating matrix polymer was then prevented and the coating delamination was inhibited, especially near the interface. At the same time, passivation of small defects can occur in the case of conductive polymers used as modifying pigment additives [83]. Moreover, yet another beneficial effect is possible, namely: the high potential of additives can inhibit the oxygen reduction reaction at the metalpolymer interface, thus preventing rapid delamination of the coating [83].

The effect of adding a conductive polyaniline polymer on the corrosion-initiated delamination of an organic coating from zinc was studied [85]. It was shown that addition of the polyanilinoemeraldine salt of para-toluenesulfonic acid (PA-PTA) to a polyvinylbutyral (PVB) coating applied on a zinc surface (30 $\mu \mathrm{m}$ thick) efficiently inhibited the corrosive (cathodic) delamination of a coating in $0.86 \mathrm{M} \mathrm{NaCl}$ solution when the electrolyte came into contact with a defect in the coating. A Kelvin scanning probe was used to determine the effect of the volume fraction of PA-PTA $\left(C_{0}\right)$ on both the delamination kinetics and the potential of the undamaged (non-delaminated) coated surface. It was shown that at relative humidity $\mathrm{RH}=95 \%$, delamination was not observed within 48 hours at $C_{0}>0.2$. However, ennoblement of the potential of the intact surface did not last longer than 6 hours at the same relative humidity. Within a similar period $(6 \mathrm{~h})$, a zinc oxide layer was formed on the surface at the metal-coating interface. The thickness of this layer was proportional to the content of the polyaniline salt [85]. An inhibition mechanism was suggested, according to which the zinc oxide layer modified with PA-PTA suppresses cathodic oxygen reduction, being itself protected from alkaline dissolution due to buffering of the solution ( $\mathrm{pH}$ stabilization) containing a polyaniline salt [85].

Thus, the use of methods for the protection from cathodic and corrosion-initiated delamination of coatings presented in the literature, namely, various methods for pretreatment of metal surfaces and modification of coatings, should efficiently inhibit the delamination of coatings and therefore reduce the risk of corrosion destruction of a metal in a coating defect.

\section{Conclusion}

The cathodic delamination of coatings is an important technical problem in the underground and underwater operation of metal structures protected from corrosion by insulating polymer coatings. A review of scientific and technical literature on the cathodic delamination of coatings is presented. The possible delamination mechanisms are considered, including the cathodic reduction of a metal oxide, electrochemical destruction of the polymer layer adjacent to the surface, and destruction of interfacial bonds exposed to chemical attack by the cathodic reaction products. The factors that determine the rate of cathodic delamination are discussed. The main methods for minimizing delamination are considered and discussed, including the treatment of the metal surface before coating application and the coating modification. 


\section{References}

1. O.O. Knudsen and A. Forsgren, Corrosion control through organic coatings, $2^{\text {nd }}$ Ed., Taylor\&Francis Group LLC, CRC Press, Boca Raton-London-NY, 2017, 254.

2. A.P. Nazarov and D. Thierry, Mechanism of the corrosion exfoliation of a polymer coating from a carbon steel, Prot. Me.t Phys. Chem. Surf., 2009, 45, 735-745. doi: 10.1134/S2070205109060173

3. W. Funke, Toward a unified view of the mechanism responsible for paint defects by metallic corrosion, Ind. Eng. Chem. Prod. Res. Dev., 1985, 24, 343-347. doi: 10.1021/i300019a001

4. H. Leidheiser, Corrosion of painted metals - A review, Corrosion, 1982, 38, no. 7, 376383.

5. H. Leidheiser, W. Wang and L. Igetoft, The mechanism for the cathodic delamination of organic coatings from a metal surface, Prog. Org. Coat., 1983, 1, 119-140. doi: 10.1016/0033-0655(83)80002-8

6. V. Cicek, Cathodic protection. industrial solutions for protecting against corrosion, John Wiley\&Sons, Inc., Scrivener Publishing LLC, Salem, Massachusetts USA, 2013, 131.

7. P.A. Schweitzer, Corrosion engineering handbook. Corrosion of linings and coatings. Cathodic and inhibitor protection and corrosion monitoring, $2^{\text {nd }}$ Ed., Tailor\&Francis Group, CRC Press, Boca Raton-London-New York, 2007, 43.

8. U.R. Evans, The electrochemical corrosion of painted steel with special reference to the alkaline peeling of the coating, J. Electrochem. Soc., 1929, 55, 243.

9. H. Leidheiser and M.W. Kendig, Conjectures on delamination of organic coatings by corrosion, Ind. Eng. Chem. Prod. Res. Dev., 1978, 17, no. 1, 54-55. doi: 10.1021/i360065a015

10. R.E. Touhsaent and H. Leidheiser, A capacitance-resistance study of polybutadiene coatings on steel, Corrosion, 1972, 28, no. 12, 435-439. doi: 10.5006/0010-931228.12 .435

11. O.D. Gonzolez, P.H. Josephic and R.A. Oriani, Undercutting of organic lacquers on steel, J. Electrochem. Soc., 1974, 129, no. 1, 29-34.

12. R.F. Hamadeh, W.J van Ooij and D.A. Dillard, A study of the mechanism of cathodic debonding of adhesively bonded neoprene rubber from steel, J. Adhesion Sci. Technol., 1988, 2, no. 2, 77-94. doi: 10.1163/156856188X00093

13. R.A. Dickie, J.S. Hammond and J.W. Holubka, Interfacial chemistry of the corrosion of polybutadiene-coated steel, Ind. Eng. Chem. Prod. Res. Dev., 1981, 20, 339-343. doi: 10.1021/i300002a021

14. J.E. Castle and J.F. Watts, Interface chemistry of stoved organic coatings, Ind. Eng. Chem. Prod. Res. Dev., 1985, 24, 361-389. doi: 10.1021/i300019a005

15. E.L. Koehler, The mechanism of cathodic disbondment of protective organic coatingsaqueous displacement at elevated $\mathrm{pH}$, Corrosion, 1984, 40, no. 1, 5-8. 
16. J.F. Watts, Mechanistic aspects of the cathodic delamination of organic coatings, $J$. Adhes., 1989, 31, 73-85. doi: 10.1080/00218468908048215

17. M. Kendig, R. Addison and S. Jeonjaquet, The mechanism of cathodic disbonding of hydroxy-terminated polybutadiene on steel from acoustic microscopy and surface energy analysis, J. Electrochem. Soc., 1990, 137, no. 9, 2690-2697.

18. G. Williams and H.X. McMurray, Chromate inhibition of corrosion-driven organic coating delamination studied using a scanning kelvin probe technique, J. Electrochem. Soc., 2001, 148, B377-B385.

19. H. Leidheiser, Cathodic delamination of polybutadiene from steel - A review, J. Adhes. Sci. Technol., 1987, 1, no. 1, 79-98. doi: 10.1163/156856187X00094

20. J. Marsh, J.D. Scantlebury and S.B. Lyon, The effect of surface/primer treatments on the performance of alkyd coated steel, Corros. Sci., 2001, 43, 829-852. doi: 10.1016/S0010938X(00)00070-6

21. M. Doherty and J.M. Sykes, Micro-cells beneath organic lacquers: a study using scanning Kelvin probe and scanning acoustic microscopy, Corros. Sci., 2004, 46, no. 5, 1265-1289. doi: $10.1016 /$ j.corsci.2003.09.016

22. J. Holub, D.T. Wong and M. Tan. Analysis of CDT methods and factors affecting cathodic disbondment, Materials of NACE Corrosion Conference and Expo CORROSION 2007, 11-15 March, Nashville, Tennessee, USA, NACE Intl. Houston TX. USA, 2007. P. 07022.

23. British standard BS 3900-F10:1985, Determination of resistance to cathodic disbonding of coatings for use in marine environments, 2008.

24. ASTM G8-96(2019), Standard test methods for cathodic disbonding of pipeline coatings.

25. ASTM G42-11(2019), Standard test method for cathodic disbonding of pipeline coatings subjected to elevated temperatures.

26. ASTM G89-85, Methods for cathodic disbonding of pipeline coatings subjected to cyclic temperatures.

27. ASTM D6190-97, Standard test method for cathodic disbonding of pipeline coatings by laboratory simulation of soil burial.

28. GOST 9.602-2016, Unified system of protection against corrosion and aging, Underground structures, General requirements for corrosion protection, Appendix, M, Standartinform, 2016, 53 (in Russian).

29. G. Wypych, Handbook of adhesion promoters, Chemtech Publishing, Toronto, 2018, 45.

30. O.O. Knudsen and J.I. Skar, Proceedings of corrosion conference and expo. Corrosion 2008, New Orleans, Louisiana, USA, NACE International. Houston TX, USA, March 16-20, 2008, 52.

31. M. Haji-Ghassemi, R.A. Cottis, K.R. Gowers and J.D. Scantlebury, Hydrogen permeation measurement on lacquer coated mild steel under cathodic polarization in sodium chloride solution, J. Oil Colour Chem. Assoc., 1992, 75, no. 7, 277-280. 
32. J. Benson and G.J. Edyvean, Hydrogen permeation through protected steel in open seawater and marine mud, Corrosion - NACE, 1998, 54, no. 9. 732-739. doi: $\underline{10.5006 / 1.3284892}$

33. A.A. Pud and G.S. Shapoval, Electrochemistry as the way to transform polymers, $J$. Macromol. Sci., Part A: Pure Appl.Chem., 1995, 32, 629-635. doi: $\underline{10.1080 / 10601329508018952}$

34. M. Kendig and D.J. Mills, An historical perspective on the corrosion protection by paints, Prog. Org. Coat., 2017, 102, Part A, 53-59. doi: 10.1016/j.porgcoat.2016.04.044

35. J. Sander, L. Kirmaier, M. Manea, D. Shchukin and E. Skorb, Anticorrosive coatings, fundamentals and new concepts, Vincentz Network, Hanover, Germany, 2010, 215.

36. M. Stratmann and W.R. Whitney, Award lecture: corrosion stability of polymer-coated metals - new concepts based on fundamental understanding, Corrosion, 2005, 61, 1115-1126. doi: $\underline{10.5006 / 1.3278148}$

37. S. Shreepathi, Physicochemical parameters influencing the testing of cathodic delamination resistance of high build pigmented epoxy coating, Prog.Org. Coat., 2016, 90, 438-445. doi: 10.1016/j.porgcoat.2015.11.007

38. J. Holub, D.T. Wong and M. Tan, Analysis of CDT methods and factors affecting cathodic disbondment, Proceedings of Corrosion Conference \& Expo, Corrosion-2007, Nashville, Tennessee, USA, 11-15 March 2007, Curran Associates Inc., NY, 2009, 8, 5199.

39. O.F. Knudsen and J.I. Skar, Cathodic disbonding of epoxy coatings - effect of test parameters, NACE Corrosion, Houston, TX, 2008, 08005.

40. J. Mark, K. Ngai, W. Graessley, L. Mandelkern, E. Samulski, J. Koenig and G. Wignall, Phys. Prop. Polym. (3rd Ed.), Cambridge University Press, Cambridge, UK, 2004, 72.

41. G.R. Kim, S.H. Lee, H.Y. Song and J.M. Han, NACE Proceedings of Corrosion Conference \& Expo, Corrosion-2007, 8, Nashville, Tennessee, USA, 11-15 March 2007, Curran Associates Inc., NY, 2009, 07013.

42. L. Zhang, X. Lu and Y. Zuo, The influence of cathodic polarization on performance of two epoxy coatings on steel, Int. J. Electrochem. Sci., 2014, 9, 6266.

43. Australian Standard AS3862-1991, External fusion-bonded epoxy coating for steel pipes, Sydney, AS, 1991.

44. G.W. Curtzwiler, E.B. Williams, A.L. Maples, S.W. Wand and J.W. Rawlins, Measurable and influential parameters that influence corrosion performance differences between multiwall carbon nanotube coating material combinations and model parent material combinations derived from epoxy-amine matrix materials, ACS Appl. Mater. Interfaces, 2017, 9, 6356-6368. doi: 10.1021/acsami.6b13469

45. G.W. Curtzwiler, E.B. Williams, A.L. Maples, S.W. Wand and J.W. Rawlins, Understanding the influence of water hydrogen bonding on the cathodic delamination rate of coated steel substrates from pre-exposure characterization, Corros. Sci., 2019, 151, 198-205. doi: $\underline{10.1016 / j . c o r s c i .2019 .01 .026}$ 
46. M.-W. Huang, C. Allely, K. Ogle, M.E. Orazem, A mathematical model for cathodic delamination of coated metal including a kinetic $\mathrm{pH}$-porosity relationship, $J$. Electrochem. Soc., 2008, 155, 279-292. doi: 10.1149/1.2884857

47. J.I. Skar and U. Steinsmo, Cathodic disbonding of paint films-transport of charge, Corros. Sci., 1993, 35, 1385-1389. doi: 10.1016/0010-938X(93)90362-K

48. H. Bi and J. Sykes, Advances in corrosion protection by organic coatings: what we know and what we would like to know, Prog. Org. Coat., 2016, 90, 114-125. doi: 10.1016/j.porgcoat.2015.10.002

49. P.A. Sorensen, K. Dam-Johansen, C.E. Weinell and S. Kiil, Cathodic delamination of seawater-immersed anticorrosive coatings: mapping of parameters affecting the rate, Prog. Org. Coat., 2010, 68, 283-292. doi: 10.1016/j.porgcoat.2010.03.012

50. M.K. Harun, J. Marsh and S.B. Lyon, The effect of surface modification on the cathodic disbondment rate of epoxy and alkyd coatings, Prog. Org. Coat., 2005, 54, 317-321. doi: 10.1016/j.porgcoat.2005.07.007

51. P.A. Sorensen, K. Dam-Johansen, C.E. Weinell and S. Kiil, Cathodic delamination: Quantification of ionic transport rates along coating-steel interface, Prog. Org. Coat., 2010, 68, 70-78. doi: 10.1016/j.porgcoat.2009.08.018

52. J.D.B. Sharman, J.M. Sykes and T. Handyside, Cathodic disbonding of chlorinated rubber coatings from steel, Corros. Sci., 1993, 35, 1375-1383. doi: 10.1016/0010938X(93)90361-J

53. P.A. Sorensen, S. Kiil, K. Dam-Johansen and C.E. Weinell, Influence of substrate topography on cathodic delamination of anticorrosive coatings, Prog. Org. Coat., 2009, 64, 142-149. doi: $10.1016 /$ j.porgcoat.2008.08.027

54. Z. Sharer and J.M. Sykes, Insights into protection mechanisms of organic coatings from thermal testing with EIS, Prog. Org. Coat., 2012, 74, 405-409. doi: 10.1016/j.porgcoat.2011.12.002

55. A. Leng, H. Streckel and M. Stratmann, The delamination of polymeric coatings from steel. Part. 1 Calibration of the Kelvin probe and basic delamination mechanism, Corros. Sci., 1999, 41, 547-578. doi: 10.1016/S0010-938X(98)00166-8

56. M. Stratmann and H. Streckel, On the atmospheric corrosion of metals which are covered with thin electrolyte layers I. Verification of the experimental technique, Corros. Sci., 30, 681-696. doi: 10.1016/0010-938X(90)90032-Z

57. J.D. Crossen, J.M. Sykes, T. Zhai and G.A. Briggs, Study of or the coating/substrate interface by scanning acoustic microscopy cathodic disbonding ofepoxy-polyamide lacquer from mild steel, Faraday Discuss., 1997, 107, 417-424. doi: 10.1039/A704693F

58. M. Stratmann, H. Streckel and R. Feser, A new technique able to measure directly the delamination of organic polymer films, Corros. Sci., 1991, 32, 467-470. doi: 10.1016/0010-938X(91)90126-A

59. H. Bi and J.M. Sykes, Cathodic disbonding of an unpigmented epoxy coating on mild steel under semi- and full-immersion conditions, Corros. Sci., 2011, 53, 3416-3425. doi: $\underline{10.1016 / j . c o r s c i .2011 .06 .021 ~}$ 
60. N.W. Khun and G.S. Frankel, Effect of hexafluorozirconic acid pretreatment on cathodic delamination of epoxy coatings from steel substrates, Corrosion, 2015, 71, 277-284. doi: $10.1016 / j$.corsci.2012.10.014

61. F. Deflorian and S. Rossi, An EIS study of ion diffusion through organic coatings, Electrochim. Acta., 2006, 51, 1736-1744. doi: 10.1016/j.electacta.2005.02.145

62. R.F. Hamade and D.A. Dillard, Assessing the effects of shear, compression, and peel on the cathodic degradation of elastomer-to-metal adhesive bonds, Int. J. Adhes. Adhes., 2005, 25, 147-163. doi: 10.1016/j.ijadhadh.2004.06.002

63. B. Ramezanzadeh and M. Rostami, The effect of cerium-based conversion treatment on the cathodic delamination and corrosion protection performance of carbon steel-fusionbonded epoxy coating systems, Appl. Surf. Sci., 2017, 392, 1004-1016. doi: $\underline{\text { 10.1016/j.apsusc.2016.09.140 }}$

64. A. Collazo, M. Izquierdo, X.R. Novoa and C. Perez, Surface treatment of carbon steel substrates to prevent cathodic delamination, Electrochim. Acta, 2007, 52, 7513-7518. doi: 10.1016/j.electacta.2007.03.004

65. J.E. Edy, H.N. McMurray, K.R. Lammers, A.C.A. deVooys, Kinetics of corrosiondriven cathodic disbondment on organic coated trivalent chromium metal-oxide-carbide coatings on steel, Corros. Sci., 2019, 157, 51-61. doi: 10.1016/j.corsci.2019.04.037

66. J. Marsh, J.D. Scantlebury and S.B. Lyon, The effect of surface/primer treatments on the performance of alkyd coated steel, Corros. Sci., 2001, 43, 829-852. doi: 10.1016/S0010938X(00)00070-6

67. M.A. Petrunin, A.P. Nazarov and Yu.N. Mikhailovskii, Electrochemical and corrosion behavior of steel, magnesium and aluminum primed with silanes, Prot. Met., 1990, 26, 749-754.

68. L.K. Wang, N.K. Shammas and Y.T. Hung, Advanced biological treatment processes, Humana Press, a part of Springer Science+Business Media, LLC, 2009, 497.

69. M.J. Owen and P.R. Dvornic, Silicone surface science, Springer, DordrechtHeidelberg-New York-London, 2012, 281.

70. B. Arkles, Silane coupling agents. Connecting across boundaries, Gelest, Inc., Morrisville, PA, USA, 2014, 78.

71. M.A. Petrunin, N.A. Gladkikh, M.A. Maleeva, L.B. Maksaeva and T.A. Yurasova, The use of organosilanes to inhibit metal corrosion, A review, Int. J. Corros. Scale Inhib., 2019, 8, no. 4, 882-907. doi: 10.17675/2305-6894-2019-8-4-6

72. M.K. Harun, J. Marsh and S.B. Lyon, The effect of surface modification on the cathodic disbondment rate of epoxy and alkyd coatings, Prog. Org. Coat., 2005, 54, 317-321. doi: 10.1016/j.porgcoat.2005.07.007

73. B. Ramezanzadeh, A. Ahmadi and M. Mahdavian, Enhancement of the corrosion protection performance and cathodic delamination resistance of epoxy coating through treatment of steel substrate by a novel nanometric sol-gel based silane composite film filled with functionalized graphene oxide nanosheets, Corros. Sci., 2016, 109, 182-205. doi: $10.1016 /$ j.corsci.2016.04.004 
74. D. Roy, G.P. Simon, M. Forsyth and J. Mardel, Modification of thermoplastic coatings for improved cathodic lisbondment performance on a steel substrate: a study on failure mechanisms, Int. J. Adhes. Adhes., 2002, 22, 395-403. doi: 10.1016/S01437496(02)00020-9

75. M. Mahdavian, R. Naderi, M. Peighambari, M. Hamdipour and S.A. Haddadi, Evaluation of cathodic disbondment or epoxy coating containing azole compounds, $J$. Ind. Eng. Chem., 2015, 21, 1167-1173. doi: 10.1016/j.jiec.2014.05.030

76. R. Naderi and M.M. Attar, Effect of zinc-free phosphate-based anticorrosion pigment on the cathodic disbondment of epoxy-polyamide coating, Prog. Org. Coat., 2014, 77, 830835. doi: 10.1016/j.porgcoat.2014.01.012

77. R. Naderi and M.M. Attar, The role of zinc aluminum phosphate anticorrosive pigment in Protective Performance and cathodic disbondment of epoxy coating, Prog. Org. Coat., 2010, 52, 1291-1296. doi: 10.1016/j.corsci.2009.12.019

78. G. Williams and H. McMurray, Inhibition of corrosion driven delamination on iron by smart-release bentonite cation-exchange pigments studied using a scanning Kelvin probe technique, Prog. Org. Coat., 2017. 102, 18-28. doi: 10.1016/j.porgcoat.2016.03.004

79. M.A. Petrunin, L.B. Maksaeva, A.A. Rybkin, N.A. Gladkikh, T.A. Yurasova, M.A. Maleeva and A.I. Marshakov, The effect of organosilanes on protective properties of polymer coatings for underground pipelines. Inhibition of cathodic peeling-off of polymer coatings from metal, Prot. Met. Phys. Chem. Surf., 2019, 55, no. 7, 1-6. doi: $\underline{10.1134 / \mathrm{S} 2070205119070128}$

80. Yu.I. Kuznetsov, Triazoles as a class of multifunctional corrosion inhibitors. A review. Part 1. 1,2,3-Benzotriazole and its derivatives. Copper, zinc and their alloys, Int. J. Corros. Scale Inhib., 2018, 1, no. 3, 271-307. doi: 2305-6894-2018-7-3-1

81. B. Ramezanzadeh, S. Niroumandrad, A. Ahmadi, M. Mahdavian and Y.M. Moghadam, Enhancement of barrier and corrosion protection performance of an epoxy coating through wet transfer of amino functionalized graphene oxide, Corros. Sci., 2016, 103, 283-304. doi: 10.1016/j.corsci.2015.11.033

82. T.F. Otero, Conducting polymers bioinspired intelligent materials and devices, Royal Society of Chemistry, Cambridge, UK, 2016, 248.

83. S.K. Ghosh, Functional coatings by polymer microencapsulation, Wiley-VCH, Weinheim, 2006, 212.

84. A. Michalik and M. Rohwerder, Conducting polymers for corrosion protection: a critical view, Zeitschrift für physikalische chemie, 2005, 219, 1547-1559. doi: 10.1524/zpch.2005.219.11.1547

85. G. Williams, R.J. Holness, D.A. Worsley and H.N. McMurray, Inhibition of corrosiondriven organic coating delamination on zinc by polyaniline, Electrochem. Commun., 6 , 2004, 549-555. doi: 10.1016/j.elecom.2004.04.004 